\title{
Levantamento de Notícias Publicadas na Internet Sobre Roubo de Carga de Medicamentos no Brasil
}

\author{
Suelen Franco Pedrotti ${ }^{1}$, Virgínia Petrini Maszlock², Tânia Alves Amador ${ }^{3}$
}

\begin{abstract}
RESUMO
Objetivo: O objetivo deste estudo é coletar dados de notícias na Internet sobre roubo de carga de medicamentos no Brasil nos anos de 2014, 2015 e 2016. Método: Uma pesquisa transversal, documental e retrospectiva foi realizada no segundo semestre de 2016, utilizando a ferramenta de busca Google ${ }^{\circledR}$ e filtros determinados pelos autores. Resultados: Foram recuperadas 3.320 notícias, das quais 288 foram analisadas e 76 incluídas no estudo. Discussão: A pesquisa demonstrou a importância de ações por todos os setores envolvidos na cadeia produtiva e na comercialização. Conclusões: Estas ações podem diminuir os roubos, além de alertar sobre a necessidade de discutir o tema entre estudantes de Farmácia e profissionais farmacêuticos.
\end{abstract}

Palavras-chave: Roubo. Fraude. Controle de medicamentos e entorpecentes. Internet.

SURVEY OF PUBLISHED NEWS ON THE INTERNET ABOUT DRUG THEFTS IN BRAZIL

\section{ABSTRACT}

Objective: Collect data from Internet news on the theft of medicines in Brazil in 2014, 2015 and 2016. Method: A cross-sectional and documental research was held in the second semester of 2016, using the mechanism of search Google ${ }^{\circledR}$ and filters determined by the authors. Results: As a result, 3320 news were recovered, which 288 were analyzed and 76 were included in the study. Discussion: The research demonstrated the importance of implementing actions for all sectors involved in the supply chain and commercialization. Conclusions: These actions can reduce the thefts. It can also alert to the need to discuss the issue among the Pharmacy students and pharmacists, avoiding harm to patients' health.

Keywords: Theft. Fraud. Drug and narcotic control. Internet.

\footnotetext{
Faculdade de Farmácia - Universidade Federal do Rio Grande do Sul. suelenpedrotti@yahoo.com.br

${ }^{2}$ Faculdade de Farmácia - Universidade Federal do Rio Grande do Sul. Programa de Pós-Graduação em Assistência Farmacêutica. virginia.maszlock@ufrgs.br

${ }^{3}$ Faculdade de Farmácia - Universidade Federal do Rio Grande do Sul. Programa de Pós-Graduação em Assistência Farmacêutica. tania.alves@ufrgs.br
} 


\section{INTRODUÇÃO}

Segundo Pinto (2016), o setor farmacêutico é um dos mais rentáveis do mundo e, de acordo com dados da empresa de pesquisa e consultoria GlobalData (2016), o faturamento aproximado em 2014 foi de US\$ 29 bilhões e o crescimento estimado é de $8,5 \%$ a cada ano, motivado pelo envelhecimento e o estilo de vida da população. A indústria farmacêutica é também uma das mais preocupadas com tecnologia, inovação e gestão de qualidade, mas pela sua grandeza econômica, é exposta a roubos e falsificações praticadas por criminosos articulados em redes extremamente lucrativas (ESQUIVEL, 2016). As rodovias com maior escoamento da produção nacional, presentes nos Estados de Rio de Janeiro e São Paulo, são as que mais sofrem ocorrências de roubo, furto ou desvio de carga (NTC\&LOGÍSTICA, 2018). Conforme dados da Associação Nacional de Transporte de Cargas e Logística, a região Sudeste é a mais afetada do Brasil, quando mais da metade dos roubos acontecem em razão do grande fluxo de cargas, uma vez que grandes laboratórios estão instalados nessa região (NTC\&LOGÍSTICA, 2016).

Fraudes no setor farmacêutico surgem de diferentes formas e oferecem sérios problemas para a saúde pública, ou oneram o setor público. Exemplo disso é a falsificação de medicamentos que vem aumentando não somente no Brasil, mas no mundo todo (MARCHETI, 2014). Produtos ilícitos expõem os usuários de medicamentos a consequências sérias, como a ineficácia do tratamento, agravando problemas de saúde preexistentes. Em 2014, Marcheti avaliou laudos de 30.452 medicamentos enviados à perícia entre 2006 e 2012 no Departamento de Polícia Federal. Destes, cerca de $60 \%$ dos medicamentos periciados não tinham registro ou licença vigente para comercialização no Brasil, e foi encontrado um porcentual de 9,7\% de falsificações.

O destino das cargas roubadas depende do tipo de medicamento. Eles podem ser vendidos irregularmente pela Internet ou mesmo serem adquiridos por farmácias ou distribuidoras para venda sem nota fiscal (ASSOCIAÇÃO..., 2015; FAGUNDES et al., 2012). Segundo Esquivel (2016), calcula-se que o mercado ilegal de fármacos, no mundo, seja da ordem de US\$70 bilhões ao ano e que metade disso seja comercializada pela Internet. Esse dado remete a outro problema de saúde pública - a automedicação -, especialmente de medicamentos que necessitam de prescrição e que trazem riscos sérios à saúde dos indivíduos. Para exemplificar a gravidade do fato, quando os fármacos de controle especial são comercializados de forma irregular, sem a devida apresentação e retenção da prescrição, dependendo da forma da situação apresentada, pode ser configurada como crime de tráfico de drogas. Espera-se que os responsáveis pela compra de medicamentos, farmacêuticos, administradores ou proprietários empreendam esforços para coibir essa prática (CONSELHO REGIONAL DE FARMÁCIA, 2015; FAGUNDES et al., 2012).

Os ilícitos praticados envolvendo cargas de medicamentos devem ser notificados fortalecendo a cadeia de informação desde os produtores até à farmácia. Segundo o sítio eletrônico da Agência Nacional de Vigilância Sanitária (Anvisa), o detentor do registro ou o distribuidor de medicamentos deve comunicar imediatamente à Vigilância Sanitária do local da ocorrência e à Anvisa, protocolando o comunicado de roubo, furto ou extravio, anexando as cópias do boletim de ocorrência, da comunicação à Vigilância local, da nota fiscal e da listagem padronizada dos produtos roubados (AGÊNCIA, 2016).

Em um relatório de 2016, publicado em seu sítio eletrônico, a Anvisa, dá ciência pública de 4.862 ocorrências de furto, roubo ou extravio de medicamentos até 11/11/2016 (AGÊNCIA, 2016). Nos últimos anos, o Brasil adotou algumas medidas para rastrear medicamentos. A lei no 11.903 , de 14 de janeiro de 2009, dispõe sobre o rastreamento da produção e do consumo de medicamentos por meio de tecnologia de captura, armazenamento e transmissão eletrônica de dados (BRASIL, 2009). Além da lei de rastreabilidade, a Anvisa expediu uma resolução normatizando essa prática por meio da Resolução no 54 , de 10 de dezembro de 2013, que "dispõe sobre a implantação do sistema nacional de controle de medicamentos e os mecanismos e procedimentos para rastreamento de medicamentos na cadeia dos produtos farmacêuticos e dá outras providências" (AGÊNCIA, 2013). Por meio do sistema de rastreio, podem-se identificar componentes do produto e seus fornecedores; verificar eventos que interfiram na qualidade do produto final; identificar clientes, fornecedores e compradores e manter a integridade de dados e a localização dos produtos (ESQUIVEL, 2016).

Apesar da questão de o roubo de carga de medicamentos ser um tema de interesse no âmbito da profissão farmacêutica, não são encontrados artigos que tratem do tema. Devemos considerar que, se há roubo, existe um mercado para a venda, ou seja, há quem adquira esses produtos. Esse tema, portanto, deve ser debatido entre os estudantes e os profissionais farmacêuticos, assim como os donos de farmácias 
e distribuidoras para conscientizar sobre a necessidade de informar e educar em duas frentes: os usuários, sobre os cuidados que devem ter ao adquirir os medicamentos; e os profissionais que adquirem medicamentos, sobre seguir boas práticas de aquisição, conhecer a legislação sanitária e a origem dos produtos disponibilizados no estabelecimento.

Ainda que os dados de roubo, furto ou extravio sejam públicos e disponibilizados nos relatórios da Anvisa, esse tema não é priorizado na mídia para alertar a população sobre o problema. Os dados disponibilizados nos portais jornalísticos na Internet, entretanto, podem servir de campo de pesquisa para análise sob o ponto de vista sanitário. Considerando esse panorama, o objetivo deste estudo foi recuperar informações sobre o roubo de cargas de medicamentos em portais de notícias disponibilizados via Internet.

\section{MÉTODO}

Trata-se de uma pesquisa transversal, documental, usando como campo de pesquisa a rede mundial de computadores (Internet) para acessar notícias publicadas em portais de notícias de livre-acesso. Os sites eletrônicos foram localizados pelo engenho de busca "Google ${ }^{\circledR ”}$, por meio do navegador Google Chrome. A pesquisa foi realizada de outubro a novembro de 2016.

Os filtros de busca utilizados na ferramenta de busca Google ${ }^{\circledR}$ foram "Notícias", "país: Brasil", "páginas em português", intervalo de três últimos anos (2016 a 2013) e "ocultar duplicações".

Foram usadas as seguintes palavras-chave:"Carga roub* medicament*" para a pesquisa. $O$ asterisco $\left(^{*}\right)$ foi empregado como um marcador para termos desconhecidos ou caracteres coringa, de acordo com a página de Ajuda de Pesquisa na Web - Operadores de Pesquisa (AJUDA DO GOOGLE, 2016), fazendo a não diferenciação de palavras no plural ou distinção de verbos conjugados, ampliando, desse modo, as possibilidades de busca. Os resultados foram classificados por relevância e analisadas as 30 primeiras páginas. Foram avaliados inicialmente pelo título e, caso não atendesse, aos objetivos a notícia era descartada. Foram selecionadas matérias jornalísticas que se referissem: a) roubo de carga de medicamentos (com ou sem apreensão); b) estabelecimentos irregulares ou que vendiam carga roubada; c) desvios do SUS; d) sonegação de impostos.

Um banco de planilhas do Excel $^{\circledR}$ foi criado para armazenar os dados da pesquisa. As principais variáveis coletadas foram: ano do evento de roubo, Estado da federação de ocorrência do evento, órgãos públicos envolvidos na apreensão, número de farmácias e de distribuidoras envoltas no evento, prejuízo relatado, tipo de medicamento roubado e destino final dos medicamentos (comércio, apreensão pela polícia, descarte, incineração, etc.). Os dados foram analisados por meio de estatística descritiva e são apresentados como frequência e análise do conteúdo das reportagens. Os trechos ilustrativos apresentaram como principais critérios para seleção: terem o nome do medicamento envolvido no roubo; da cidade; do envolvimento de farmacêutico; e irregularidades nas farmácias indicativas de venda de carga roubada.

\section{RESULTADOS E DISCUSSÃO}

A busca no Google resultou, inicialmente, em 3.320 resultados (manchetes) em 62 páginas, tendo sido avaliadas as primeiras 30 páginas, das quais foram selecionadas 76 notícias para compor este estudo. O processo completo de seleção das notícias é apresentado na Figura 1. Mesmo tendo sido selecionada a opção "ocultar duplicações", foi necessária a exclusão manual de resultados, porque se tratavam do mesmo evento, relatado por sites de notícias diferentes.

Figura 1 - Fluxograma da seleção de notícias sobre roubo de carga de medicamentos publicados na Internet entre outubro e novembro de 2016 e recuperadas nesta pesquisa

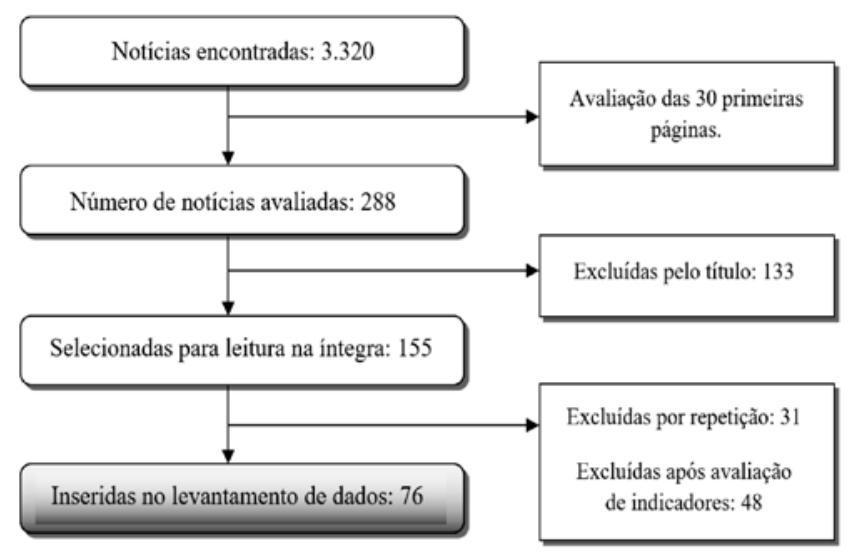

Fonte: Elaborado pelas autoras, 2016.

Foram selecionadas 76 notícias para compor o estudo. Em relação ao ano de publicação, 34 foram publicadas em 2016, 29 em 2015, 12 em 2014 e uma em 2013. Os resultados sobre unidade da federação onde ocorreu o roubo, os órgãos envolvidos e o destino dos medicamentos são apresentados na Tabela 1. 
Tabela 1 - Distribuição geográfica das notícias sobre roubo de carga de medicamentos, órgãos envolvidos nos eventos e destinos dos medicamentos

\begin{tabular}{|c|c|c|}
\hline \multicolumn{2}{|l|}{ Localização geográfica } & \multirow{2}{*}{$f$} \\
\hline Distribuição por UF $(f)$ & Região & \\
\hline SP (23); MG (18); RJ (7); ES (3) & Sudeste & 51 \\
\hline $\begin{array}{c}\mathrm{AL}(1) ; \mathrm{BA}(1) ; \mathrm{CE}(3) ; \mathrm{MA}(1) ; \mathrm{PE}(3) ; \mathrm{PB} \\
\text { (1); SE (2) }\end{array}$ & Nordeste & 12 \\
\hline DF (1); GO (6); MS (3); MT (1) & Centro-Oeste & 11 \\
\hline AC (2); PA (2); TO (1) & Norte & 5 \\
\hline PR (5) & Sul & 5 \\
\hline Órgão envolvido & & $f$ \\
\hline Polícia Civil & & 37 \\
\hline Polícia Militar & & 27 \\
\hline Polícia Rodoviária Federal & & 15 \\
\hline Vigilância Sanitária & & 8 \\
\hline Polícia Federal & & 4 \\
\hline Polícia (não especificado) & & 4 \\
\hline Guarda Municipal & & 3 \\
\hline Ministério Público (estadual/federal) & & 3 \\
\hline Secretarias estaduais (saúde/fazenda) & & 3 \\
\hline Receitas (estadual/federal) & & 2 \\
\hline Outros (Funed/Bombeiros) & & 2 \\
\hline Destino dos medicamentos & & $f$ \\
\hline Apreensão & & 56 \\
\hline Incineração & & 3 \\
\hline Perícia & & 1 \\
\hline $\mathrm{NI}$ & & 16 \\
\hline
\end{tabular}

Fonte: Elaborado pelas autoras, 2016.

Nota: Funed = Fundação Ezequiel Dias; NI= não informado.

Neste estudo os Estados com maior ocorrência de roubo de carga de medicamentos foram São Paulo, Minas Gerais e Rio de Janeiro. Das 27 unidades federativas do Brasil, entretanto, 19 foram citadas em reportagens, representando todas as regiões do país. A Região Sudeste apresenta um maior número de notícias sobre roubo de carga de medicamentos, compatível por ser um centro de produção e distribuição desses produtos. A ausência de notícias nos demais Estados não significa que nestes não ocorram roubos de carga de medicamentos, apenas que os mesmos não apareceram nas reportagens selecionadas para análise.

Os órgãos públicos mais envolvidos nas ações contra roubos e outras irregularidades foram a Polícia Civil e a Polícia Militar. Outros órgãos públicos também foram citados, como o Ministério Público e a Vigilância Sanitária, geralmente em ações conjuntas com as polícias. Em apenas 56 casos os medicamentos foram recuperados; houve o envolvimento de farmácias em 11 casos e das distribuidoras de medicamentos em 7 .

Operações conjuntas entre vigilância sanitária, conselhos de farmácia e polícia civil, têm sido uma estratégia para evitar irregularidades sanitárias e penais. O Conselho Regional de Farmácia do Rio Grande do Sul (CRF-RS) tem realizado com frequência essas ações, encontrando e apreendendo medicamentos sem qualquer indicação de procedência, quando os responsáveis pelo estabelecimento não apresentam documentos comprobatório da legalidade na aquisição dos medicamentos, incluindo os de venda estritamente controlada com a devida retenção de receituário médico (CONSELHO REGIONAL DE FARMÁCIA, 2016).

A venda de medicamentos sem procedência deve ser entendida aqui como "sem nota fiscal", que é o documento que comprova a procedência. Os casos do envolvimento de farmácias estavam relacionados com denúncias ou inspeções realizadas pela polícia e Vigilâncias Sanitárias locais. Nessas foram encontrados medicamentos controlados sem nota fiscal, comprovando a aquisição ilegal desses produtos, conforme a legislação especifica (AGÊNCIA, 1998). A venda de medicamentos adquiridos sem procedência é considerada crime de acordo com o Código Penal Brasileiro que, em seu artigo 273 , trata da falsificação, corrupção, adulteração ou alteração de produto destinado a fins terapêuticos ou medicinais (BRASIL, 1940). Não somente a venda em si, mas o código também considera crime expor à venda, ter em depósito para vender ou, de qualquer forma, distribuir ou entregar a consumo medicamento falsificado, corrompido, adulterado ou alterado. Esta prática é considerada um crime grave e se enquadra no artigo 10 da Lei 8.072, de 25 de julho de 1990, que dispõe sobre os crimes hediondos, nos termos do artigo 50, inciso XLIII, da Constituição Federal (BRASIL, 1990).

Hurtado e Lasmar (2014), que conduziram estudo sobre medicamentos falsificados, mostraram que em $90 \%$ dos estabelecimentos onde ocorriam crimes, como venda de medicamento falsificado, não havia a efetiva presença de farmacêutico; em outros, a drogaria ou farmácia era totalmente clandestina, sem os registros sanitários necessários. Nos casos de estabelecimentos legais, é imprescindível que o farmacêutico participe do controle de estoque de medicamentos, inclusive conhecendo a origem dos produtos. A procedência do medicamento pode ser comprovada pela nota fiscal de compra, documento que protege o profissional de incorrer nesses crimes e este deve mantê- 
-las arquivadas para fins de fiscalização e comprovação. As fiscalizações em farmácias e drogarias podem ser sinalizadores para investigações, sejam da Anvisa ou da Polícia Civil, por denúncias ou ainda nas inspeções de rotina da Vigilância Sanitária. Nas inspeções, o agente pode solicitar verificação das notas fiscais dos medicamentos contidos no estabelecimento para fins de comprovação de sua procedência. Além dos aspectos legais, os profissionais farmacêuticos possuem responsabilidade na garantia da qualidade dos produtos e na segurança dos pacientes.

A atuação do farmacêutico também se dá no transporte e distribuição dos medicamentos, com regulamentação disposta na Resolução no 365, de 2 de outubro de 2001, do Conselho Federal de Farmácia (CFF), que dispõe sobre a assistência técnica farmacêutica em distribuidoras, representantes, importadoras e exportadoras de medicamentos, insumos farmacêuticos e correlatos (CONSELHO FEDERAL DE FARMÁCIA, 2001). É responsabilidade do farmacêutico cumprir as normas e legislações profissional e sanitária, manter as boas práticas estabelecidas, bem como responder ética e legalmente por atos praticados em contrariedade à Resolução (CONSELHO FEDERAL DE FARMÁCIA, 2014; BRASIL, 2014).

Sobre a origem de produtos vendidos sem nota fiscal, há indícios de contrabando do Paraguai e de roubo de cargas nas rodovias do Brasil. Segundo Hurtado e Lasmar (2014), medicamentos apreendidos em operações conjuntas pela polícia e vigilância sanitária eram contrabandeados e falsos, e $49 \%$ dos medicamentos apreendidos eram fabricados pela indústria paraguaia, sugerindo que os produtos falsos são produzidos no exterior e adentram no país por meio da fronteira (ASSOCIAÇÃO..., 2015; HURTADO; LASMAR, 2014).

O trecho da notícia a seguir ilustra a participação de farmácias na recepção de medicamentos de origem irregular.

A Polícia Civil apreendeu mais de 100 caixas de medicamentos de uso controlado [...] Região Centro-Sul de Belo Horizonte. O farmacêutico responsável pelo local e a dona da farmácia foram presos em flagrante e autuados [...]. $O$ órgão municipal recebeu uma denúncia de funcionamento de uma farmácia sem alvará do setor sanitário e solicitou o apoio da Polícia Civil para averiguar o caso [...]. Os policiais descobriram que remédios de uso psiquiátrico, de tarja preta [...] estavam sendo vendidos sem receita. "O farmacêutico e a dona do estabelecimento confessaram as duas situações e agora vamos investigar de onde vinham os medicamentos", afirma o delegado, vinculado ao Departamento Estadual de Investigação de Fraudes [...] (ESTADO DE MINAS ON-LINE, 2016).

Deve-se considerar que as cargas roubadas, ao entrarem no mercado, podem estar sendo comercializadas nos estabelecimentos de saúde. No estudo de Hurtado e Lasmar (2014) foram efetuadas 659 prisões em flagrante. Dentre os presos, cerca de $70 \%$ foram os proprietários dos estabelecimentos inspecionados e $15 \%$ os farmacêuticos responsáveis técnicos. Os consumidores necessitam ser conscientizados dos riscos que estes medicamentos podem oferecer à saúde. O farmacêutico é um elo importante neste processo, pois necessita conhecer os procedimentos legais necessários para o funcionamento de uma farmácia, desde os alvarás sanitários até as certidões de regularidade do estabelecimento e de assistência de um responsável técnico registrado junto ao ConseIho Regional de Farmácia. Também deve realizar as movimentações de medicamentos controlados pelo Sistema Nacional de Gerenciamento de Produtos Controlados (SNGPC) e conhecer a legislação sanitária atualizada. Na pesquisa de Hurtado e Lasmar (2014), $36 \%$ dos locais interditados foram motivados por ausência de alvará sanitário e registro no órgão sanitário, bem como locais sem mínimas condições de higiene ou capacidade satisfatória de funcionamento.

Para além das questões profissionais, o setor industrial farmacêutico atribui à informalidade os danos para o desenvolvimento do setor. Para a sociedade, os danos aparecem em forma de sonegação de impostos. No Estado do Rio Grande do Sul, por exemplo, é aplicado ICMS de $18 \%$ sobre medicamentos, correspondendo a $34 \%$ do preço final do produto. Um estudo do Instituto Brasileiro de Ética Concorrencial (Etco) sugere que em torno de $23 \%$ de todos os impostos devidos são sonegados, o que representaria aproximadamente R\$ 2-3 bilhões a menos por ano aos cofres públicos. Por isso, a segurança da cadeia de abastecimento de medicamentos é uma preocupação primordial para a indústria farmacêutica, e a efetivação da legislação de rastreabilidade pode oferecer maior segurança tanto aos produtores quanto aos consumidores desses produtos (INSTITUTO..., 2005).

Entre os medicamentos apreendidos ou encontrados em diligências das polícias e denúncias verificadas pela vigilância sanitária, encontram-se os de classes farmacológicas, ou indicação terapêutica, que também são relacionados frequentemente com falsificações. De acordo com Ames e Souza (2012), os medicamentos para tratamento de câncer são su- 
jeitos à falsificação e, neste estudo, observamos a ocorrência desta categoria de medicamentos em cinco reportagens. Também estão sujeitos os anabolizantes, analgésicos e os medicamentos controlados para tratamento de disfunção erétil e emagrecedores, com quatro notícias cada. Também foram noticiados sobre outras 18 classes de medicamentos, mas com menos de três casos.

Os fármacos usados para o tratamento de câncer no Sistema Único de Saúde (SUS) muitas vezes são desviados para o mercado informal, sendo vendidos dentro ou fora do país. Alguns medicamentos são comercializados pela Internet, como os anabolizantes, emagrecedores e medicamentos para disfunção erétil, principalmente. No estudo de Hurtado e Lasmar (2014), por exemplo, 78\% dos produtos apreendidos consistiam de medicamentos com indicação para disfunção erétil. Os preços mais baixos, a automedicação irresponsável, a aquisição de medicamentos de prescrição sem a necessidade de receita médica, a facilidade de compra e o anonimato, estão entre os motivos de venda pela internet (INTERFARMA, 2016). Os trechos a seguir exemplificam os tipos de medicamentos encontrados nas reportagens analisadas.

A segunda parte da "Operação Máfia do Cytotec" foi realizada na manhã desta quarta-feira, 18, e cumpriu mandados de busca e apreensão, além de prender dois homens [...] foram apreendidos 2,1 mil caixas de medicamentos [...] onde foi autuada em flagrante por venda de substância medicamentos de procedência ignorada e por venda de medicamentos vencidos. Durante as investigações, a Polícia descobriu que eles distribuíam os remédios em toda a região do Cariri e nos Estados do Piauí e da Paraíba [...] De acordo com o delegado municipal do Crato, [...] o material não possuía nota fiscal. "Os remédios não possuem notas fiscais, a procedência é desconhecida. Isso torna o caso um crime hediondo. Como não se sabe nem a procedência, não podemos afirmar se são medicamentos verdadeiros ou falsos", declarou. A primeira etapa ocorreu no início de fevereiro, com a prisão de duas pessoas responsáveis pela venda do remédio abortivo $\mathrm{Cy}$ totec, no Crato (O POVO ON-LINE, 2015).

Uma carga de produtos para coquetel anti-HIV, avaliada em $\mathrm{R} \$ 1$ milhão, foi apreendida dentro de um caminhão, na tarde desta quinta-feira, durante uma operação da Delegacia de Roubos e Furtos de Cargas (DRFC) na comunidade da Quitanda, em Costa Barros, Zona Norte do Rio. Segundo a Polícia Civil, o material foi recuperado integralmente e o roubo do veículo com carga foi registrado na terça-feira. Os agentes chegaram ao caminhão roubado após investigações [...] (O DIA ON-LINE, 2015).

Um homem de 35 anos foi preso na tarde dessa segunda-feira (4) pela Polícia Federal (PF) de Bauru após ser flagrado transportando centenas de cartelas de medicamentos com venda e distribuição proibidas no Brasil. Entre os produtos apreendidos estavam anabolizantes, remédios para emagrecimento, abortivos e estimulantes sexuais trazidos do Paraguai e que seriam distribuídos na cidade de Ribeirão Preto [...] (JORNAL DA CIDADE ON-LINE, 2015).

Segundo estimativas da Associação Brasileira de Redes de Farmácias e Drogarias (Abrafarma), de 10\% a $15 \%$ dos medicamentos em circulação são provenientes de roubos, contrabando, falsificação e produtos sem registro (INTERFARMA, 2016). Muitos medicamentos que circulam no mercado informal são de comercialização restrita, como os anabolizantes, que são prescritos, em alguns casos, com indicação médica, e fármacos usados para interromper a gravidez, de uso restrito hospitalar, como o Cytotec $^{\circledR}$, citado na reportagem anterior. O estudo de Marcheti (2014) encontrou falsificação confirmada em $9,7 \%$ dos medicamentos analisados, principalmente aqueles para disfunção erétil $(40,2 \%)$, esteroides anabólicos $(32,2 \%)$ e andrógenos $(15,8 \%)$. As falsificações foram confirmadas, principalmente, por divergências do número de lote, problemas na embalagem e ausência do fármaco declarado (MARCHETI, 2014). São, portanto, produtos que, por si só, podem trazer graves riscos à segurança do usuário, pois apresentam potencial de risco à saúde e, adicionado a isso, não se conhece a qualidade da fabricação e armazenamento e a composição, que pode ser alterada.

Aliás, o armazenamento dos produtos de roubos é outro fator complicador nessa cadeia de abastecimento de medicamentos. Seguem exemplos de reportagens que abordaram o armazenamento de carga de medicamento apreendida.

A Polícia Civil acredita que as 185 caixas com remédios que foram apreendidas no bairro Nossa Senhora da Conceição, em Contagem, na região metropolitana de Belo Horizonte, na madrugada de ontem, tenham sido roubadas. Os remédios estavam acondicionados em uma casa, que a polícia teve acesso após denúncia anônima. Um inquérito foi instaurado para investigar a origem dos produtos, mas ninguém foi preso. A maioria dos medicamentos - entre eles remédios para febre, gripe e azia - estava dentro do prazo de validade, porém, devido às péssimas condições 
de armazenamento, alguns remédios estavam com as embalagens mofadas ou amassadas [...] (PORTAL CAPARAÓ ON-LINE, 2016).

Operação conjunta do Grupo de Atuação Especial de Combate ao Crime Organizado (Gaeco), Agência Nacional de Vigilância Sanitária (ANVISA) e Polícia Militar (PM) resultou na prisão de 12 pessoas e na apreensão de grande quantidade de medicamentos de alto custo, na manhã dessa quinta-feira (19). Os nomes dos envolvidos não foram divulgados pelos responsáveis pela ação. Somente em Bauru, foram cerca de R\$ 4 milhões em remédios recolhidos em depósitos e residências de integrantes da quadrilha. Boa parte da mercadoria, destinada ao tratamento de câncer, estava armazenada de maneira precária, sem a devida refrigeração [...] (JORNAL DA CIDADE ON-LINE, 2016).

Para conter o avanço de roubos e evitar perda de mercadorias, os empresários do setor têm investido em seguros para o fretamento e sistemas de segurança nos caminhões e nas cargas. Este aumento de custo é repassado ao preço final do medicamento. As seguradoras estão cada vez mais exigentes com as transportadoras, aplicando aumento de valores de sinistros, exigindo escoltas armadas e, muitas vezes, se recusando a fazer o transporte de cargas de alto valor. Conforme a NTC\&Logística (2016), as empresas investem cerca de $12 \%$ de seu faturamento em segurança do transporte, o que é acrescido no preço final do produto.

As cargas de medicamentos são muito visadas pelo alto valor agregado, e o setor empresarial envolvido calcula que as perdas anuais ultrapassem a casa dos bilhões de reais, considerando-se apenas as mercadorias. Segundo informações levantadas nas reportagens deste estudo, os prejuízos das empresas variaram de $\mathrm{R} \$ 2$ mil até $\mathrm{R} \$ \mathbf{5}$ milhões. Além dos prejuízos individuais por carga, em algumas reportagens a informação citava o prejuízo anual ou de vários Estados juntos. E o maior prejuízo noticiado foi de $\mathrm{R} \$ 500$ milhões.

As cargas de produtos sujeitos à Vigilância Sanitária, quando recuperadas, são apreendidas e passam por perícia (ESQUIVEL, 2016). De acordo com o Manual de Bens Apreendidos, da Corregedoria Nacional de Justiça, os medicamentos objetos de contrabando ou descaminho são periciados para identificação da origem da mercadoria e destinados à Receita Federal para destruição (CONSELHO NACIONAL DE JUSTIÇA, 2016). Ainda, aqueles medicamentos proibidos no Brasil, segundo o artigo 95 da Portaria no 344, de 12 de maio de 1998, que aprova o Regulamento Técnico sobre substâncias e medicamentos sujeitos a controle especial, devem ser guardados sob responsabilidade da Autoridade Policial competente, que fará a solicitação de incineração à Autoridade Judiciária (AGÊNCIA, 1998). Os medicamentos devem ser descartados conforme orientações do manual de Gerenciamento dos Resíduos dos Serviços de Saúde da Anvisa (AGÊNCIA..., 2006).

Por fim, algumas reportagens foram encontradas com relatos de desvios de hospitais públicos e do SUS. Os trechos a seguir exemplificam os dados sobre os tipos de medicamentos encontrados nas reportagens analisadas.

A Polícia Civil apreendeu 1.040 caixas do medicamento Selozok $^{\circledR} 50 \mathrm{mg}$, lote 35650 , durante a operação Pharmacus em Campo Grande. Em entrevista coletiva nesta segunda-feira (22), a titular da Delegacia Especializada de Combate ao Crime Organizado (Deco), Ana Claudia Medina, afirmou que as unidades integram carga roubada que seria destinada para o Sistema Único de Saúde (SUS) [...] (G1 GLOBO ON-LINE, 2015).

Três pessoas foram presas em Sorocaba, São Paulo, por desviarem medicamento de alto custo do principal hospital da região. O remédio usado no tratamento de crianças com dificuldade no crescimento seria vendido como anabolizante. A polícia suspeita que o grupo agia em várias cidades. [...] De acordo com as investigações, o prejuízo estimado na saúde do estado passa dos $\mathrm{R} \$ 3$ milhões. Segundo a Corregedoria, mesmo com o desvio dos remédios nenhuma criança ficou sem receber os medicamentos [...] (G1 GLOBO ONLINE, 2016).

O resultado desta pesquisa sobre roubo de carga de medicamentos é de interesse para diferentes campos da sociedade, como a academia, para debater entre os estudantes, a vigilância sanitária, os farmacêuticos em atividade no serviço público e em farmácias privadas. Uma limitação do estudo, entretanto, foi analisar as 30 primeiras páginas da pesquisa no Google. Esse fato pode ter suprimido a ocorrência de reportagens no Rio Grande do Sul e outros Estados e não significa que não tenham havido roubos ou mesmo reportagens nos Estados que não apareceram na pesquisa. De qualquer forma, como mencionado, é relevante suscitar o debate sobre esse tema em todo o país e entre todos os envolvidos na cadeia de produção e consumo do produto.

\section{CONCLUSÃO}

Com base nos dados obtidos na pesquisa, conclui-se pela importância do debate sobre roubo de cargas de medicamentos por todos os setores da so- 
ciedade envolvidos. A cooperação, verificada neste estudo, entre órgãos públicos, como a Vigilância Sanitária, as Polícias Federal, Militar, Rodoviária, o Ministério Público e os Conselhos Regionais de Farmácia, parece ser eficaz para localizar os produtos roubados e identificar classes farmacológicas que tenham maior potencial para retornarem ao mercado ilegalmente. Também foi possível concluir que, apesar de haver mais reportagens na região Sudeste, a ocorrência de roubo é distribuída em todo o Brasil e a prevenção aos roubos de carga de medicamentos deve ser um esforço conjunto de governos, laboratórios produtores, distribuidores e dos partícipes na comercialização do produto, pois os riscos à saúde da população são inestimáveis, além do preocupante prejuízo à arrecadação dos Estados e municípios.

A responsabilidade na atuação do profissional farmacêutico é muito importante quando se trata de aquisição de medicamentos para os estabelecimentos de saúde, bem como no transporte e distribuição desses produtos. Ainda, os órgãos de fiscalização competentes possuem ação fundamental, realizando inspeção e atuando na fiscalização de combate ao crime de roubo e falsificação de medicamentos. A população é um elo importante nessa cadeia e talvez a mais vulnerável e, portanto, precisa ser alertada e conscientizada sobre o assunto, procurando evitar o consumo de medicamentos envolvidos em processos ilegais e de procedência duvidosa.

\section{REFERÊNCIAS}

AGÊNCIA NACIONAL DE VIGILÂNCIA SANITÁRIA (Anvisa). Gerenciamento dos resíduos dos serviços de saúde. Brasília: Anvisa, 2006. Disponível em: <http://www.ANVISA.gov.br/ servicosaude/manuais/manual_gerenciamento_residuos. pdf>. Acesso em: 27 nov. 2016.

. Ministério da Saúde. Roubos, furtos e extravios.

Brasil. Disponível em: <http://portal.ANVISA.gov.br/roubos-furtos-e-extravios>. Acesso em: 24 nov. 2016.

. Resolução no 54, de 10 de dezembro de 2013. Dispõe sobre a implantação do sistema nacional de controle de medicamentos e os mecanismos e procedimentos para rastreamento de medicamentos na cadeia dos produtos farmacêuticos e dá outras providências. Diário Oficial da União, 11 dez. 2013.

. Portaria no 344, de 12 de maio de 1998. Aprova o Regulamento Técnico sobre substâncias e medicamentos sujeitos a controle especial. Diário Oficial da União, $31 \mathrm{dez}$. 1998.

AJUDA DO GOOGLE. Operadores de pesquisa. 2016. Disponível em: <https://support.google.com/websearch/ answer/2466433 ?visit_id=1-636149190344838412312977523\&rd=1>. Acesso em: 16 nov. 2016.
AMES J.; SOUZA, D. Z. Falsificação de medicamentos no Brasil. Rev. Saúde Pública, São Paulo, v. 46, supl. 1, p. 154-159, dez. 2012. Disponível em: <http:// www.scielo.br/scielo.php?script=sci_arttext\&pi$\mathrm{d}=$ S0034-89102012000100019\&Ing=en>. Acesso em: 25 nov. 2016.

ASSOCIAÇÃO BRASILEIRA DE DISTRIBUIÇÃO E LOGÍSTICA DE PRODUTOS FARMACÊUTICOS (Abradilan). Cerco aos receptadores, de 8 de outubro de 2015. Disponível em: <http:// www.abradilan.com.br/index.php? $m=$ noticiaFE\&id_noticia=2265>. Acesso em: 14 jun. 2018.

BRASIL. Lei no 13.021, de 8 de agosto de 2014. Dispõe sobre o exercício e a fiscalização das atividades farmacêuticas. Diário Oficial da União, 11 ago. 2014.

. Lei no 12.894 , de 17 de dezembro de 2013. Acrescenta inciso $\mathrm{V}$ ao art. 10 da Lei $\mathrm{n}$ - 10.446, de 8 de maio de 2002, para prever a atribuição da Polícia Federal para apurar os crimes de falsificação, corrupção e adulteração de medicamentos, assim como sua venda, inclusive pela internet, quando houver repercussão interestadual ou internacional. Diário Oficial da União, 18 dez. 2013. Disponível em: <http://www.planalto.gov.br/ccivil_03/_Ato20112014/2013/Lei/L12894.htm>. Acesso em: 6 jun. 2018.

. Lei no 11.903 , de 14 de janeiro de 2009. Dispõe sobre o rastreamento da produção e do consumo de medicamentos por meio de tecnologia de captura, armazenamento e transmissão eletrônica de dados. Diário Oficial da União, 2009. 15 jan. 2009. Disponível em: <https://www.planalto. gov.br/ccivil_03/_Ato2007-2010/2009/Lei/L11903.htm>. Acesso em: 16 nov. 2016.

. Lei no 8.072, de 25 de julho de 1990. Dispõe sobre os crimes hediondos, nos termos do art. 5o, inciso XLIII, da Constituição Federal, e determina outras providências. Diário Oficial da União, 26 jul. 1990.

. Decreto-Lei no 2.848, de 7 de dezembro de 1940. Código Penal. Diário Oficial da União, 31 dez. 1940.

CONSELHO FEDERAL DE FARMÁCIA (CFF). Código de Ética da Profissão Farmacêutica. 2014. Disponível em: <http:// www.cff.org.br/userfiles/file/resolucoes/596.pdf $>$. Acesso em: 15 jun. 2018.

. Resolução no 365 de 2 de outubro de 2001. Dispõe sobre a assistência técnica farmacêutica em distribuidoras, representantes, importadoras e exportadoras de medicamentos, insumos farmacêuticos e correlatos. Disponível em: <http://www.cff.org.br/userfiles/file/resolucoes/365.pdf>. Acesso em: 23 nov. 2016.

CONSELHO NACIONAL DE JUSTIÇA (CNJ). Manual de bens apreendidos. 2016. Disponível em: <http://www.ic.pr.gov. $\mathrm{br} /$ arquivos/File/MANUAL_DE_BENS_APREENDIDOS_CNJ. pdf $>$. Acesso em: 27 nov. 2016.

CONSELHO REGIONAL DE FARMÁCIA (CRF-RS). Fiscalização, notícias. Ação entre CRF-RS e Decon resulta em prisão em Alvorada, em 2016. Disponível em: <http://www.crfrs. org.br/portal/pagina/fiscalizacao-noticias-detalhes.php?idn=1979>. Acesso em: 27 nov. 2016. 
CONSELHO REGIONAL DE FARMÁCIA (CRF-RS). Orientação técnica informa: dispensação de medicamentos controlados pela Portaria no 344/98, de 9 de dezembro de 2015. Disponível em: <https://www.crfrs.org.br/portal/pagina/ noticias-detalhes.php?idn=1720>. Acesso em: 15 jun. 2018. ESQUIVEL, C. L. W. Tratamento jurídico-penal das fraudes farmacêuticas no âmbito da saúde pública brasileira na atualidade. 2016. Tese (Doutorado) - Universidade Federal do Paraná, Curitiba, 2016.

ESTADO DE MINAS ON-LINE. Polícia apreende mais de 100 caixas de medicamentos controlados de farmácia sem alvará. 2016. Disponível em: <http://www.em.com.br/app/ noticia/gerais/2016/04/06/interna_gerais,750751/policia-apreende-mais-de-100-caixas-de-medicamentos-controlados-de-far.shtml>. Acesso em: 13 nov. 2016.

FAGUNDES, L. L. et al. Comércio llegal de Medicamentos pela Internet: um estudo de caso. 2012. THE INTERNATIONAL CONFERENCE ON FORENSIC COMPUTER SCIENCE (ICoFCS) 2012, p. 33. Disponível em: <http://icofcs. org/2012/ICoFCS2012_05.pdf.>. Acesso em: 15 jun. 2018.

G1 GLOBO ON-LINE. Hora 1, Notícia. Polícia investiga desvio de remédio de alto custo de hospital de Sorocaba. [Internet]. 2016. Disponível em: <http://g1.globo.com/hora1/ noticia/2016/01/policia-investiga-desvio-de-remedio-de-alto-custo-de-hospital-de-sorocaba.html>. Acesso em: 8 nov. 2016.

- Mato Grosso do Sul, Notícia. Em operação, polícia de MS apreende 1.040 remédios vendidos após roubo. 2015. Disponível em: <http://g1.globo.com/mato-grosso-do-sul/noticia/2015/06/em-operacao-policia-de-ms-apreende-1040-remedios-vendidos-apos-roubo.html>. Acesso em: 3 nov. 2016.

GLOBALDATA. Mercado farmacêutico brasileiro deve atingir US\$48 bilhões em 2020. Portal Setor Saúde. 2016. Disponível em: <https://setorsaude.com.br/mercado-farmaceutico-Brasileiro-deve-atingir-us-48-bilhoes-em-2020/>. Acesso em: 24 nov. 2016.

HURTADO, R. L.; LASMAR, M. C. Medicamentos falsificados e contrabandeados no Brasil: panorama geral e perspectivas de combate ao seu consumo. Cad. Saúde Pública, Rio de Janeiro, v. 30, n. 4, p. 891-895, abr. 2014.

INSTITUTO BRASILEIRO DE ÉTICA CONCORRENCIAL - Etco (Brasil). 2005. Informalidade no setor farmacêutico: barreira ao crescimento da economia brasileira e risco à saúde pública. São Paulo, 2005. 37 p.

INTERFARMA. Informalidade na saúde: o que está em jogo é a vida. São Paulo: Edições Especiais Saúde. 2016. Disponível em: <http://www.interfarma.org.br/uploads/biblioteca/96-informalidade-na-saadesite.pdf $>$. Acesso em: 24 nov. 2016.
JORNAL DA CIDADE ON-LINE. Polícia. Operação desarticula bando e alerta pra venda de remédios "estragados". [Internet]. 2016. Disponível em: <http://www.jcnet.com.br/Policia/2016/05/operacao-desarticula-bando-e-alerta-para-venda-de-remedios-estragados.html>. Acesso em: 10 nov. 2016.

. Regional. Polícia apreende em Jaú cargas de remédios proibidos no país. 2015. Disponível em: <http://www. jcnet.com.br/Regional/2015/05/policia-apreende-em-jau-carga-de-remedios-proibidos-no-pais.html>. Acesso em: 14 nov. 2016.

MARCHETI, R. G. A. Avaliação da falsificação de medicamentos a partir dos dados de laudos periciais do Departamento de Polícia Federal no Brasil no período de 2006 a 2012. 2014. Dissertação (Mestrado em Ciências Farmacêuticas) - Universidade de Brasília, Brasília, 2014.

NTC\&LOGÍSTICA. NTC divulga estatística de roubo de cargas em 2017. São Paulo: Associação Nacional do Transporte de Cargas e Logística. Disponível em: <http://www.portalntc. org.br/outros/ntc-divulga-estatistica-de-roubo-de-cargas-em-2017/59596>. Acesso em: 4 jun. 2018.

. Como se ressarcir das despesas de gerenciamento de riscos [Internet]. São Paulo: Associação Nacional do Transporte de Cargas e Logística. Disponível em: <http:// www.portalntc.org.br/blogdoneuto/como-se-ressarcir-das-despesas-de-gerenciamento-de-riscos/57582>. Acesso em: 24 nov. 2016.

O DIA ON-LINE. Notícia, Rio de Janeiro. Carga com produtos para coquetel anti-HIV é apreendida em Costa Barros. 2015. Disponível em: <http://odia.ig.com.br/noticia/rio-de-janeiro/2015-04-02/carga-com-produtos-para-coquetel-anti-hiv-e-apreendida-em-costa-barros.html>. Acesso em: 8 nov. 2016.

O POVO ON-LINE. 2015. Ceará. Dupla é presa com mais de 2 mil caixas de medicamentos. Disponível em: <http:// www.opovo.com.br/app/ceara/crato/2015/03/18/notcrato,3409332/dupla-e-presa-com-mais-de-2-mil-caixas-de-medicamentos.shtml>. Acesso em: 14 nov. 2016.

PINTO, C. P. A rastreabilidade no contexto da gestão da qualidade. 2016. Dissertação (Mestrado) - Universidade Federal de Itajubá, Programa de Pós-Graduação em Ciências em Engenharia de Produção, Itajubá, 2016.

PORTAL CAPARAÓ ON-LINE. 2016. Notícias. Polícia Civil apreende 185 caixas de remédios roubados. Disponível em: <http://www.portalcaparao.com.br/noticia/21029/policia-civil-apreende-185-caixas-de-remedios-roubados>. Acesso em: 13 nov. 2016. 